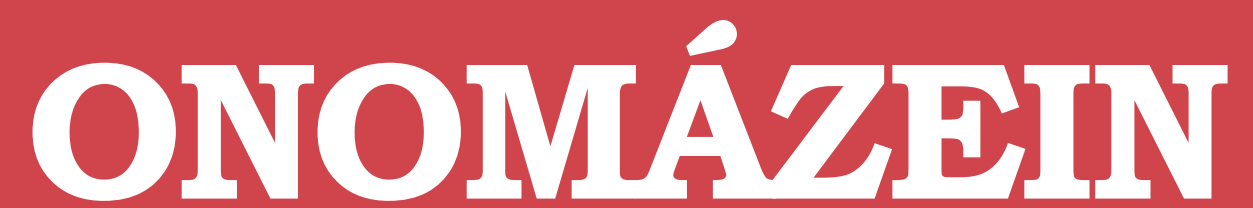

Revista semestral de lingüística, filología y traducción
PONTIFICIA UNIVERSIDAD CATÓLICA DE CHILE FACULTAD DE LETRAS

\title{
La teoría del marco de memoria-predicción y los cognits en el origen y la organización cortical del lenguaje
}

Memory-prediction framework theory and cognits in language's origin and cortical organization

\section{Miguel Ángel Martín-Pascual}

Universitat Autònoma

de Barcelona

España

\section{Celia Andreu-Sánchez}

Universitat Autònoma

de Barcelona

España

ONOMÁZEIN 28 (diciembre de 2013): 14-28

DOI: 10.7764/onomazein.28.8

Miguel Ángel Martín-Pascual: Grupo de investigación Neuro-Com, Neurociencia y Comunicación, Departamento de Comunicación Audiovisual y Publicidad, Facultad de Ciencias de la Comunicación, Universitat Autònoma de Barcelona. Correo electrónico: miguelangel.martin@uab.cat

Celia Andreu-Sánchez: Grupo de investigación Neuro-Com, Neurociencia y Comunicación, Departamento de Comunicación Audiovisual y Publicidad, Facultad de Ciencias de la Comunicación, Universitat Autònoma de Barcelona. Correo electrónico: celia.andreu@uab.cat 


\section{Resumen}

Tradicionalmente se consideraba al lenguaje como ejemplo de fenómeno cultural y social, en contraposición a lo natural o biológico. Esta distinción de lo cultural adquirido (nurture) frente a lo natural (nature) refleja, en realidad, la brecha previa entre las dos culturas de las ciencias humanas y naturales que Snow pretendía solucionar ya en 1951. Hoy se considera que el lenguaje tiene una profunda base biológica con pruebas bien asentadas en la comunidad científica. Para afirmar que la facultad del lenguaje depende de los genes, parece que hace falta un marco más amplio de comprensión de la cognición humana donde el lenguaje se integraría con el resto de procesos cognitivos neurogenéticos y neurofisiológicos en la interacción de la humanidad con la realidad.

Palabras clave: genética del lenguaje; cognits; memorias temporales jerárquicas; teoría del marco de memoria-predicción.

\section{Abstract}

Traditionally, language was regarded as an example of a cultural and a social phenomenon, as opposed to a natural or a biological one. This distinction of culturally acquired (nurture) against the naturally (nature) reflects, in fact, the previous gap between the two cultures of human and natural sciences that Snow tried to solve since 1951. Today it is considered that the language has a deep biological basis with well- established evidence in the scientific community. For the assertion that the power of language depends on the genes, it is needed a more comprehensive understanding of human cognition where language would be integrated with other neurogenetic cognitive processes and neurophysiological interaction between humanity and reality.

Keywords: genetics of language; cognits; hierarchical temporal memory; memory-prediction framework theory. 


\section{Introducción}

El problema del origen del lenguaje es uno de los desafíos de la biología en el siglo XXI. La explicación de Darwin de una transición gradual, un continuo progresivo desde los gritos de los animales hasta un lenguaje humano parece hoy cuestionable, aunque seres humanos y primates pueden compartir la fase previa de comunicación, el protolenguaje. Las explicaciones gradualistas baldwinianas no son satisfactorias. Es verdad que compartimos ciertos circuitos neurológicos básicos dedicados al lenguaje con los animales, circuitos que aparecen en la neurogénesis en los niños humanos. Puede que en esta última coincidencia se encuentre la posibilidad de explicar el salto al lenguaje humano, si podemos explicar cómo se organiza el lenguaje humano en el cerebro. Hay autores que establecen un paralelismo en la categorización del lenguaje y otros sistemas de percepción, como el visual. El protolenguaje se halla en circuitos sinápticos muy próximos a los flujos visuales. De hecho, es un lugar común hablar de las corrientes dorsales, el dónde, y ventrales, el qué, en el sistema de visión (Milner y Goodale, 2006). Ambas ramas están próximas y junto con otras vías de flujos perceptivos; parece inevitable establecer un paralelismo con dicha rama dorsal y el área de Broca, dedicada a la sintaxis, y la ventral, cerca del área de Wernicke, dedicada a la decodificación semántica (Givon, 2002).

\section{Marco teórico}

El gradualismo de Baldwin (Richards, 1987), en el sentido de una progresión paulatina de desarrollos comunicativos que van incorporándose al genoma a través de mutaciones casuales con la implementación a grupos seleccionados por su éxito de cohesión social, parece desafiar lo que sabemos sobre lo abrupto de la aparición del lenguaje. Es lo que Ramachandran denomina el segundo gran salto de la humanidad. Él opina que la clave está en las neuronas espejo, que, en las nacientes concentraciones sociales de población, facilitaron el aprendizaje y desarrollo acelerado (Ramachandran, 2000). El camino de la exaptación no parece explicar el proceso. Muchas características sofisticadas del lenguaje no parecen remitir a funciones de ventaja selectiva. Ha sido fácil la tentación de atribuir al origen del lenguaje un factor externo originado casi exclusivamente por la cultura. Es la polémica del paso de los genes a los memes de Dawkins (1989). Parece de sentido común que la cultura es un producto social, pero eso es una tautología que no explica por qué o qué provocó ese salto de habilidades cognitivas en la humanidad. Para evitar el concepto de una mutación monstruosa o una especulación no científica, hasta ahora, en el origen del lenguaje se postula algún tipo de evolución gradual. En cambio, los estudios genéticos más fiables, por ejemplo, Cavalli-Sforza (1996), estableciendo un paralelismo entre el árbol del ADN mitocondrial y el grafo de las lenguas, postulan que el lenguaje se produjo de una sola vez y en el centro de África, donde la población humana era mayor. Por otro lado, muchos lingüistas y estudiosos culturales creen que el lenguaje no tiene que ver con la biología, sino que sería un producto cultural. Un ejemplo de ello sería la tradición estructural-antropológica representada por Baker. Habría tantas lenguas como culturas (Baker, 1996). Hoy todavía, pensadores como Alva Noë creen que la capacidad lingüística nunca es un producto neuronal. Noë afirma que el lenguaje es una práctica cultural compartida (Noë, 2009). En realidad, el punto de vista de Noë remite a su concepto de conciencia asociada a la realidad externa, sin lo que la mente no podría existir. De ahí a sugerir que la mente está fuera del cerebro sólo hay un paso silogístico. Y es lógico aparentemente, pero no aclara cómo podemos procesar esa capacidad. Hoy, la genética del comportamiento, introduciendo la idea de un papel activo de los genes en la conducta, se abre paso sin dejar a un lado la idea de que lo natural y lo aprendido se complementan. Parece claro que el potencial de aprendizaje de los seres vivos está programado por la estructura del cerebro (Wilson, 1978). Estamos programados para 
aprender cierto tipo de estímulos, no podemos procesar algunos y otros son neutrales a nuestras capacidades (Longa, 2003).

Hasta ahora, se destacaban sobre todo tres argumentos que bucean en la base biológica del lenguaje con solidez, a saber:

El poderoso argumento del defensor del innatismo lingüístico, Noam Chomsky (1959), el de la pobreza del estímulo, que parece justificar el innatismo biológico del lenguaje. Chomsky recuerda la facilidad con la que aprenden a hablar los niños, sobre todo a estructurar y sofisticar el lenguaje, a pesar de los pocos y fragmentarios estímulos que reciben de los padres. Además, la adquisición del lenguaje tiene una ventana de aprendizaje limitada en el tiempo: más allá de un periodo crítico, de una edad determinada, su adquisición es mucho más difícil, como experimenta cualquier adulto que quiere aprender una segunda lengua. También, todos los lenguajes de las distintas poblaciones humanas son complejos, y hay correlatos neurales ligados a esta capacidad, como nuestra mejor habilidad para discriminar contenidos lingüísticos de otros sonidos en nuestro aparato auditivo (Longa, 2003). Parece que el lenguaje es parte del equipo biológico de la especie humana.

En segundo lugar, para reforzar este punto de vista, si se afirma que el genotipo, el equipamiento biológico original, afecta a las predisposiciones o habilidades que el individuo pueda adquirir, también hay que contemplar el fenotipo, las manifestaciones finales del individuo desarrollado según la interacción de los genes con el ambiente. Puede que las características de las distintas lenguas no estén codificadas en el genoma, pero este sí condiciona la estructura de adquisición. Entre genotipo y fenotipo, pues, hay que contar con los fenómenos epigenéticos de interacción entre genes y ambiente, que nos alejan del determinismo y, en concreto, desactivan el determinismo genético en las enormes combinaciones y manifestaciones de la cognición humana. También por este camino aparece una predisposición a la estructura del lenguaje en la especie humana.

Por último, es verdad que hoy no conocemos nada sobre cómo se transmiten en los genes, y por consiguiente en la síntesis de proteínas, las capacidades del lenguaje. Pero tenemos indicios firmes de esta transmisión en el posible hallazgo de genes unidos a las capacidades lingüísticas y la morfogénesis en áreas que se dedican habitualmente al lenguaje, en los estudios de Gopnik (1990), Fisher (Fisher y otros, 1998) o Lai (Lai y otros, 2001), donde se observan que deficiencias hereditarias llevan a déficits aparentemente localizados en el lenguaje. Luego, si hay un componente innato en el lenguaje, deberíamos encontrar fallos hereditarios que se manifiesten como deficiencias en capacidades lingüísticas. Efectivamente, con el estudio de tres generaciones de una familia inglesa, denotada como KE, Gopnik encontró que algunos de sus miembros, la mitad de ellos, tenían problemas gramaticales (Gopnik, 1990). Carecían de reglas para la formación genérica de plurales y debían aprender la forma plural de las palabras como piezas léxicas diferentes. El tiempo pasado y el género provocaban problemas semejantes. Contrastando con otras familias en países diferentes se observó que, aunque no era un trastorno totalmente homogéneo, persistía un grupo común de problemas puramente gramaticales en ausencia de factores causales conocidos como sordera, retraso cognitivo, daño neural sobrevenido o autismo (Longa, 2003). El síndrome, además, no se producía en grados. La herencia era responsable de esta alteración y su transmisión a la progenie. En sucesivas investigaciones, el equipo de Fisher detectó una región en el cromosoma 7, $\mathrm{SPCH}$, en los afectados de la misma familia que no se presentaba en los familiares no afectados o en el resto de la población (Fisher y otros, 1998). Lai concretó estos resultados localizando el defecto de la familia KE en un gen de esa región que Ilamaron FOXP2 (Lai y otros, 2001). Este podía ser, por tanto, el primer gen directamente vinculado 
al lenguaje. Parece un gen de tipo regulador y los autores defienden que en su alteración de la función proteica (en concreto un nucleótido de guanina reemplazado por adenina, provocando un cambio de aminoácidos sustituyendo la arginina por histidina) se manifiesta un desarrollo anormal de las estructuras neurales relevantes para el lenguaje.

A pesar de estas evidencias y estando totalmente de acuerdo con su significado, en cuanto a las pruebas que suponen para la base genética del lenguaje, no estamos de acuerdo en que los genes codifican tejido neural específicamente dedicado al lenguaje en el sentido sintáctico y totalmente diferenciado del resto de tejidos neurales. El marco debe ser más amplio, o el concepto de lenguaje debe ser ampliado, pues el sustrato común de las capacidades de cognición es el factor determinante en estos y otros déficits de la capacidad de modelizar y actuar sobre la realidad en distintas manifestaciones de la cognición.

El camino hacia las teorías de especialización funcional del cerebro se abrió en el siglo XIX con la vulgarizada frenología de Gall, que aun así lanzaba una hipótesis razonable de la organización funcional del cerebro y la conducta. Dos de los hitos más importantes de esta corriente de especialización de las áreas y funciones cerebrales, hoy modernizada y dominante, fueron establecidos por los hallazgos de Broca y Wernicke, ya citados más arriba. El camino hacia el modelo localizacionista-conexionista ha demostrado su utilidad hasta la fecha (Hernández y Tormos, 2004). Pero el modelo tenía muchas derivaciones en el perfil y las manifestaciones psicológicas de los pacientes. Había muchas variaciones en las áreas y conexiones implicadas que nos introducían en un modelo más complejo de afasias que, durante el siglo XX, condujeron a la imposibilidad de encontrar correlatos neurales localizados para todos los daños neurológicos. La asociación de factores de conciencia, motivación, emoción o contexto de aparición variable y presente en muchos casos de déficit ha llevado a una coincidencia de teorías holistas y conexionistas en la actualidad. El descubrimiento de los variados sistemas de compensación para suplir las tareas afectadas, tanto de interacción como de plasticidad neuronal, ha planteado una situación mucho más compleja. La plasticidad, de hecho, representa una potencialidad que no siempre es la óptima en términos funcionales de compensación (Hernández y Tormos, 2004). El conexionismo tractográfico pone de manifiesto un holismo que, con las nuevas técnicas de neuroimagen, muestra un sustrato cognitivo distribuido en el córtex en estructuras compartidas que parecen jugar un papel fundamental en las distintas manifestaciones del aprendizaje y la memoria. El análisis de los mecanismos cognitivos necesita encontrar una explicación no localizacionista en el proceso mental básico. En este camino, algunos factores de trastorno específico del lenguaje serían un problema de procesamiento cognitivo como otros déficits no adquiridos de aprendizaje. Esto refuerza la postura de los que creen difícil que tengamos genes implicados en el cerebro de manera tan específica que sólo afecten al lenguaje. Puede que haya mecanismos cognoscitivos más generales y básicos, que tengan mayor o menor importancia en las manifestaciones del lenguaje (Salas, 2003).

\section{Aportaciones recientes al tema: memorias temporales jerárquicas y cognits}

En la base de todo el problema con el lenguaje está el concepto de aprendizaje. Si el punto de vista tradicional de adquisición del lenguaje consistía en el trasvase de la experiencia del exterior a una tabula rasa interior que aprende de la práctica, el nuevo punto de vista propugna un aprendizaje por selección, donde el aprendizaje se filtra a través de las capacidades preexistentes del cerebro y sus genes. Este aprendizaje relativiza en cierta manera el papel de la experiencia (Longa, 2003). Lo que harían los estímulos externos es disparar o activar rasgos innatos 
preexistentes en la especie. El lenguaje quedaría integrado así en el esquema neurofisiológico, evolutivo y genético general.

Muchas veces, aunque sea para defender el papel biológico en la capacidad lingüística, se afirma que el lenguaje y la cognición son entidades disociadas puesto que una deficiencia cognitiva puede acompañar a una función lingüística que no esté afectada y viceversa (Longa, 2003). Esto no es así a nivel de procesamiento neuronal. Parece, como veremos, que la capacidad del lenguaje es una habilidad cognitiva enmarcada en el funcionamiento global del cerebro humano, coincidente con otras habilidades y que responde a las capacidades comunes de categorización, memorización y modelización del mundo que ejecuta el neocórtex humano, la capa evolutivamente más moderna del cerebro, en muchos de sus aspectos cognitivos.

A partir de la transdisciplinariedad necesaria de los estudios sobre el origen del lenguaje, parece superada la contraposición entre naturaleza (nature) y educación (nurture). El factor genético puede estar presente, pero el surgimiento de herramientas como el lenguaje está indisolublemente unido a la categorización previa de la percepción global en interacción con la memoria, como defienden diversos autores en distintos desarrollos neurocientíficos (Hawkins y Blakeslee, 2004; Ramachandran, 2000, 2006, 2011; Ramachandran y Oberman, 2006; Fuster, 2003; Rizzolati, 2006; Edelman, 2006; entre otros).

\subsection{La teoría del marco de memoria-predicción}

Jeff Hawkins lanzó en 2004 su teoría del marco de memoria-predicción (MPF, del inglés Memory-Prediction Framework). Intentando, por un lado, explicar el fallo del desarrollo de sistemas de memoria artificial (Al) en los ordenadores y, por otro, cómo realmente podemos comprender la inteligencia, propugnó una teoría sobre cómo trabaja el cerebro para procesar estímulos externos y aprender (Hawkins y Blakeslee, 2004).
Hawkins opina que es un gran error creer que la inteligencia se define por un comportamiento inteligente. Los seres humanos pueden ser inteligentes sin manifestarlo. Cree que el cerebro usa mayoritariamente sus recursos de memoria para crear un modelo del mundo. Todo lo que sabemos y aprendemos está incorporado al modelo. Y el cerebro usa este modelo memorístico para hacer continuas predicciones de los eventos futuros. Para Hawkins el cerebro funciona memorizando patrones para efectuar predicciones continuamente. Señala cómo todo el neocórtex es bastante uniforme en apariencia y estructura. Apoyándose en los estudios neurofisiológicos de Mountcastle (1978, 1997, 1998), muestra cómo las regiones del córtex que gestionan las aferencias auditivas se parecen a las que gestionan el tacto, el control muscular, el área del lenguaje de Broca, y cualquier otra región del córtex. Mountcastle sugirió que, puesto que todas esas regiones son parecidas, puede que estén realizando la misma operación y propone que el córtex usa un algoritmo común para cumplir todo lo que hace. Es cómo están conectadas las regiones lo que define su función cognitiva aparentemente diferente. $Y$ a pesar del interés por averiguar las sutiles diferencias en la estructura, también habría que explorar el otro camino, ver las coincidencias en el esquema. Si nuestros genes determinan cómo se conectan las células del córtex, lo que es específico para su función y cada especie, el tejido cortical, en cambio, estaría haciendo lo mismo en todas partes. Si Mountcastle tenía razón, el algoritmo de funcionamiento debería poder expresarse independientemente de funciones 0 sentidos, ya sea vista, oído o lenguaje. Tenemos conocimiento de la gran flexibilidad del sistema y cómo a partir de los genes se desarrollan funciones especializadas basadas en los estímulos e informaciones recibidas durante el desarrollo. Conectadas las regiones en jerarquía, mediante este algoritmo, el cerebro aprenderá de su entorno.

Un cerebro humano, desarrollado con nor- 
malidad, puede aprender cualquiera de las miles de lenguas que existen. Ese mismo cerebro puede aprender lenguaje de signos, escrito, musical, matemático, de programación o lenguaje corporal. La asimetría funcional hemisférica del cerebro se encuentra en muchas especies y es preexistente a la especialización. Tenemos un área visual que parece dedicada específicamente a representar letras y dígitos escritos. ¿Significa que hemos nacido con esa área lingüística preparada para procesar esas letras y números? El lenguaje escrito es una invención demasiado reciente para que nuestros genes incorporen un mecanismo específico para ello (Hawkins y Blakeslee, 2004). Hay un sistema flexible que permite cambios en función de los estímulos. En conocidos experimentos con hurones, las fibras del nervio óptico fueron reconducidas al área auditiva. Expuestos dichos hurones a patrones visuales, su área auditiva desarrolló campos receptivos visuales y fueron capaces de generar comportamiento usando esta "audio-visión". Sus vías visuales nuevas veían con tejido cerebral que habitualmente oía sonidos (Melchner y otros, 2000). Por otro lado, los estudios de sustitución sensorial, trasplantando tejido visual en ratas a una zona que usualmente representa el sentido del tacto, llevan a que el tejido trasplantado acabe procesando sensaciones táctiles (Bach-y Rita, 2004). Varias pruebas apoyan la existencia de un algoritmo cortical común. En los humanos, nada refleja tan bien las capacidades de plasticidad cerebral del equipamiento para el lenguaje que su recuperación funcional tras grandes lesiones en el hemisferio izquierdo. En estos casos, se ha demostrado que, excepto recuperación funcional del tejido dañado, otras regiones corticales o subcorticales se hacen cargo de esa habilidad (Fuster, 2003). No olvidemos los clásicos estudios sensoriales con miembros fantasma en amputados de Ramachandran (Ramachandran y otros, 1995).

Hawkins, de manera previa al modelo MPF, considera tres factores comunes al proceso cognitivo: el factor temporal en la comprensión de los procesos cerebrales, pues el flujo de información nunca es estático; la importancia de la retroalimentación (feedback) presente en el córtex por doquier, y, como característica estructural del neocórtex, la jerarquía. No es necesaria ninguna combinación de sentidos para obtener inteligencia mientras el cerebro pueda elaborar patrones invariantes sucesivos de su entorno. La teoría MPF puede resumirse en los siguientes puntos fundacionales (Hawkins y Blakeslee, 2004; Dileep, 2008):

1. El neocórtex construye modelos para los patrones espaciales y temporales a los que se expone perceptualmente. La finalidad de esta construcción de modelos es la predicción del próximo patrón entrante.

2. El córtex está organizado en una repetida unidad básica de computación conocida como el circuito canónico cortical. Desde un punto de vista computacional, este circuito canónico puede considerarse como un nodo que está replicado multitud de veces.

3. El córtex está organizado jerárquicamente. Esto significa que los nodos - las unidades de computación básicas - están conectados en una jerarquía arborescente.

4. La función del córtex es crear modelos del mundo del que recibe estímulos. El modelo es construido usando una jerarquía espacial y temporal memorizando patrones y secuencias en todos los nodos de la jerarquía. El modelo se usa para hacer predicciones sobre los estímulos entrantes.

5. El neocórtex construye su modelo del mundo autónomamente, sin supervisión.

6. Cada nodo de la jerarquía guarda un gran número de patrones y secuencias. El método de reconocimiento de patrones empleado por el córtex está basado en el almacenamiento de multitud de patrones.

7. Los outputs de un nodo son secuencias de 
patrones aprendidas previamente.

8. La información transita arriba y abajo en la jerarquía para reconocer y desambiguar la información y se propaga adelante en el tiempo para predecir el próximo patrón entrante.

En resumen, el neocórtex guarda secuencias de pautas, recupera asociaciones de modelos automáticamente, los almacena en formas invariantes y en una jerarquía. El neocórtex no sería un ordenador calculando en paralelo o en serie. En lugar de procesar respuestas para problemas concretos, usaría memorias almacenadas, no cálculos, para resolver problemas y producir comportamientos. Una prueba de esto sería intentar recitar el alfabeto al revés. Es difícil, pues no lo hemos experimentado con anterioridad habitualmente. La memoria del alfabeto sería una secuencia de patrones, no es algo recuperado arbitrariamente.

\subsection{Los cognits y la sintaxis del lenguaje}

Joaquín Fuster, en este sentido, propone que casi todo el aprendizaje consiste en la formación de redes cognitivas en el córtex. Fuster llama cognits a unidades de estas redes cognitivas. Estos mecanismos de asociación usarían una plataforma de conexiones preexistentes o innatas ligando uniones neuronales en los más altos niveles semánticos y conceptuales del córtex. Muchos cognits de la corteza prefrontal están preparados para implementar la sintaxis de las acciones motoras, y también lo están para implementar la sintaxis del lenguaje. Si estas reglas son asociaciones contingentes de unidades cognitivas, cognits, podría existir un aparato cortical innato para las reglas de la gramática, pero también común en procesos de aprendizaje (Fuster, 2003). Hay una cierta evidencia de que las reglas de los procesos genéticos y la memoria asociativa operan para procesar diferentes formas gramaticales, por ejemplo los verbos regulares frente a los irregulares (Pinker, 1991). Aparentemente dos enfoques diferentes, el genético y el aprendizaje, vuelven a ser complementarios. Es bien conoci- do que el desarrollo del lenguaje en los niños se corresponde con el desarrollo de las habilidades motoras. El procesamiento de cognits de asociación nos lleva de nuevo a Mountcastle y Hawkins y sus patrones jerárquicos. El área de Broca sería homóloga a otra región filogenéticamente más antigua en el lóbulo frontal izquierdo especializada en el manejo de herramientas e instrumentos (Greenfield, 1991).

\subsection{La organización del neocórtex y el lenguaje}

A nivel neurofisiológico, las pruebas de una estructura común del neocórtex provienen de los estudios histológicos y las primeras grabaciones de neuronas individuales en gatos y monos entre 1949 y 1955 (Mountcastle, 2003). El córtex se organiza horizontalmente en seis capas y verticalmente agrupa neuronas en sinapsis a lo largo de las capas horizontales. La unidad básica en el neocórtex maduro sería la minicolumna, una cadena estrecha de neuronas extendiéndose verticalmente a lo largo de las capas II a VI (Mountcastle, 1998). Las minicolumnas, con una dimensión transversal de 40-50 $\mu \mathrm{m}$, contendrían la mayoría de fenotipos neurales interconectados en vertical, y estarían unidas en columnas que agruparían entre 50-80 minicolumnas. Estas minicolumnas son muy similares en distintas áreas corticales. Se diferencian en conectividad o transmisores sinápticos, y uno de los desafíos actuales de la neurociencia sería conocer cómo están ligadas estas unidades en diferentes áreas corticales y relacionadas dinámicamente con los sistemas distribuidos del neocórtex. Sin embargo, el 90\% de la sinapsis de las células de cada columna viene de lugares ajenos a ella, ya sean otras columnas cercanas o conexiones que recorren medio cerebro. La citoarquitectura del neocórtex estaría compuesta de pequeñas unidades, circuitos neuronales locales repetidos sin cesar que varían en el tipo de células, en la conexión externa o entre bloques, pero el diseño básico y la operación es la misma (Mountcastle, 1997). La minicolumna se considera hoy un mo- 
delo sólido de organización cortical (Buxhoeveden y Casanova, 2002). Hawkins cree que las columnas son la unidad base de predicción y su jerarquía interior es la base del modelo de predicción-memoria (Hawkins y Blakeslee, 2004). El lenguaje encajaría en la MPF sin ninguna maquinaria diferente al resto de procesos cognitivos. Si entendemos el lenguaje como la capacidad del cerebro de codificar la información y traducirla en ideas y señales neurales específicas para mejorar sus esquemas de comunicación y recordamos que el lenguaje permite al cerebro humano categorizar la información, agrupar acciones, organizar el tiempo y planear el futuro (RamosZúñiga y Villaseñor-Cabrera, 2011), realmente la sintaxis y semántica del lenguaje no es diferente de la estructura jerárquica de otros objetos cotidianos. Y si entendemos la palabra como un código que establece la conexión entre el sonido y su significado, las palabras habladas y escritas son patrones en la propia realidad (Hawkins y Blakeslee, 2004). Asociamos palabras habladas con nuestra memoria de sus equivalentes físicos y semánticos. El lenguaje necesita un gran neocórtex y también requiere un córtex motor y una musculatura desarrollada para reproducir y articular sonidos y gestos.

Parece más fructífero el camino que explica el lenguaje a partir de la nueva organización del neocórtex humano. Esto permite explicar esa coincidencia de vías ventrales y dorsales y parece coincidente no sólo con la organización de los flujos de entrada de la percepción, sino también con la jerarquización de la información y el modelo operativo de la realidad que construye el cerebro. No olvidemos que un niño, como citamos en el argumento de la pobreza del estímulo, puede desarrollar el lenguaje a partir de estímulos gestuales o verbales muy pobres. Los enunciados lingüísticos ocultan la estructura de las oraciones, que tienen una rígida organización jerárquica, rápidamente aprendida por el infante. Es la propia estructura de evolución general del cerebro humano la que permite expresar las categorías del lenguaje.

\section{Contrastaciones empíricas de la MPF, las redes cognitivas y el lenguaje}

En la discusión sobre las raíces genéticas del lenguaje siempre regresamos al problema original, por ejemplo, cualquier lengua en que lea un ser humano activará en el hemisferio dominante para el lenguaje un área, en el córtex temporal inferior, dedicada a la imagen y forma de las palabras. Parece que existe un sistema neuronal específico para el lenguaje en el reconocimiento de letras y otras anotaciones matemáticas o musicales (Sacks, 2010). ¿Por qué tenemos esa habilidad innata para leer si la escritura es un invento relativamente reciente en términos genéticos y evolutivos? Está claro que aunque esta área parezca diseñada para el acto de leer, no evolucionó para este propósito específicamente. Vivimos en un mundo de estímulos de todo tipo. Como hemos visto, clasificar el mundo para sobrevivir necesita de una jerarquía de modelos. No vemos las cosas como son, sino que vemos patrones, bordes, contornos y superficies. Es necesario extraer patrones invariantes de los estímulos cambiantes e interpretarlos en distintas circunstancias. No podemos guardar en nuestra memoria las millones de variaciones existentes en la presentación de los objetos. Necesitamos una colección finita de patrones que permitan muchas combinaciones. Como las letras del alfabeto. Durante el neurodesarrollo hay cosas, como las caras, que son aprendidas rápidamente. Pero buena parte del mundo lo aprendemos con la actividad y la experiencia, usando millones de neuronas que tienen una gran plasticidad solamente para el reconocimiento de patrones visuales. Estos circuitos de formación de patrones invariables pueden ser reclutados para el reconocimiento de caracteres escritos. De hecho, los sistemas de escritura comparten ciertas características topológicas con el entorno y la forma de las letras han sido seleccionadas para rememorar los conglomerados de contornos que encontramos en los entornos naturales, aprovechando nuestros ya existentes mecanismos de reconocimiento (Changizi y otros, 2006). Nuestro 
cerebro sólo aceptaría un número limitado de formas y patrones. El lenguaje no aparece como una adaptación evolutiva directa, depende de la plasticidad cerebral y su invención usa, con metáforas brillantes o patrones y modelos, una predisposición neural preexistente.

\subsection{La teoría de la memoria temporal jerárquica}

La propuesta de patrones de aprendizaje de la MPF, como esquema de funcionamiento explicativo, sin embargo, ha sido también criticada. Se dice que es una teoría incompleta y que otorga demasiada importancia a la memoria en el proceso cognitivo (Feldman, 2005). Por otro lado, Eric Kandel, en las reseñas del libro On Intelligence (Hawkins y Blakeslee, 2004), cree que es reveladora para el futuro de máquinas inteligentes. Hasta ese momento, la teoría MPF formulada por Hawkins era una teoría biológica. Dileep con la ayuda de Hawkins se ocupó de los algoritmos matemáticos complementarios a esta teoría (Dileep y Hawkins, 2005; Dileep, 2008). Bautizaron al sistema de algoritmos y explicación más global como teoría de la memoria temporal jerárquica (HTM, del inglés Hierarchical Temporal Memory).

A partir de la concepción de Hawkins sobre los principios diferenciales de funcionamiento entre los ordenadores y la mente humana, los primeros programados, la segunda auto-aprendiendo, él mismo desarrolló con George Dileep $(2005,2008)$ una serie de algoritmos que permiten a una máquina aprender y hacer modelos progresivamente más sofisticados siguiendo su teoría de organización HTM del neocórtex humano. A partir de una empresa creada por el propio Hawkins - creador en el pasado del software y hardware de los ordenadores de mano Palm-, Ilamada Numenta, y su propia fundación de investigación, el Redwood Neuroscience Institute, lanzaron una plataforma de software de reconocimiento visual, actualizada constantemente, siguiendo los algoritmos de la HTM (Hawkins y otros, 2011). El software no se programa, se en- trena, exponiéndose a un flujo de datos sensoriales. En el experimento inicial, se comenzó presentando 3 objetos. Dileep dibujó un gato, una oveja y un helicóptero, cargó el algoritmo y entrenó al ordenador. Dileep introdujo variaciones en los objetos, versiones que la máquina nunca había visto. La máquina situó las imágenes en las categorías correctas, aprendiendo, e, incluso, estimó la probabilidad de acierto con que lo hacía (Dileep, 2008). Las propiedades predictivas del sistema HTM reflejan el modelo de neocórtex que propugna Hawkins para el que predicción e inferencia cognitiva es casi lo mismo y es parte integral de cómo funciona una región de HTM (Hawkins y otros, 2011). De esta manera, las características de las predicciones con procesos cognitivos y de aprendizaje serían:

1. La predicción es un fenómeno continuo a cualquier nivel. En el caso del lenguaje, regiones inferiores podrían predecir los próximos fonemas, y niveles superiores, palabras o frases completas.

2. La predicción acontece en todas las regiones y niveles de la jerarquía.

3. Las predicciones son sensibles al contexto, copiando nuestras experiencias en el mundo real. No se predice lo inmediato, sino muchos pasos por delante. Puede que se vuelva a replantear algunos patrones o la predicción sigue avanzando, generando predicciones más estables que los estímulos entrantes. De hecho, conceptos más globales, como el nombre de una canción, cambian más despacio que las notas que vamos escuchando y anticipando de la canción.

4. Las predicciones Ilevan a la estabilidad, pero las regiones de HTM son en realidad detectores de novedades que se apartan de los modelos de predicción.

5. Una predicción nos dice si una nueva entrada o estímulo es esperada o inesperada. Si una HTM está procesando lenguaje hablado, debería predecir que sonidos, palabras e ideas van a recibirse. Esta predicción rellena los huecos 
(fill in) de datos perdidos, despeja ambigüedad y hace el sistema más robusto al ruido.

Todo el comportamiento estaría influido por nuestras percepciones. Las entradas sensoriales y el comportamiento motor están íntimamente unidos, de tal manera que la mayoría de regiones en el neocórtex presentan una eferencia motora, incluso las de nivel sensorial más bajo. Hawkins y Dileep no han conseguido integrar aún comportamientos motores en su modelo de software.

Tras el misterio del lenguaje hay un algoritmo común que utiliza la misma circuitería cerebral que otras partes del neocórtex. Con el proceso de hominización en las zonas prefrontales, motivación y aprendizaje debían procesar semejantemente muchas habilidades. El lanzamiento de un objeto para hacer blanco en un animal exige un complejo cálculo mental que al activarse utiliza los mismos circuitos que el cálculo que permite la producción verbal (Serrano, 2003). Es conocido el paralelismo entre la actividad de la mano, la boca, la lengua y la laringe. Puede que el cálculo mental y social esté asociado a la sintaxis en la estructura del proceso, igual que el reconocimiento visual o las predicciones que veíamos más arriba.

\subsection{La validación de los cognits}

Por su parte, Joaquín Fuster presentó en las conferencias Almaden de IBM en 2006 un trabajo de recopilación de estímulos agrupando multitud de experimentos de varios centros de investigación sobre memoria de trabajo visual, espacial y verbal (Fuster, 2006). Este meta-análisis gráfico presenta en tiempo real las sucesivas o recurrentes activaciones de las redes de memoria en el córtex visual, áreas auditivas, dorsal prefrontal, cingulado anterior, órbito-frontal, etc. La teoría de Fuster de los cognits como redes corticales de representación, una especie de qualias, o cualidades subjetivas de experiencias propias, físicos y tangibles, presenta mayor solidez neurocientífica y una explicación complementaria de las acciones motoras (percepción y acción) frente al modelo de Hawkins. Pero los resultados del software HTM son innegables y presentan un futuro de desarrollo en inteligencia artificial (AI) después de muchos intentos fallidos.

Para Fuster, las claves de las redes de memoria serían las siguientes (Fuster, 2006):

1. El código de la memoria es relacional. Las redes de memoria, cognits, son asociaciones entre agrupaciones de neuronas más o menos dispersas en el neocórtex. No se emplea el concepto de columna neuronal

2. Las redes de memoria perceptual están organizadas jerárquicamente en el córtex posterior. Las redes de memoria ejecutiva, en el córtex frontal.

3. El córtex prefrontal, en la cúspide del ciclo de acción-percepción, media los sucesos temporales con su integración ejecutiva de la memoria de trabajo.

4. Esa memoria de trabajo es mantenida por la actividad recurrente entre el córtex prefrontal y las áreas asociativas del córtex posterior.

En la dinámica de la memoria de trabajo, para la obtención de un fin, es fundamental la mediación temporal entre acciones y percepciones (Fuster, 2006), recordando la teoría MPF:

SIAHORAESESTO, ENTONCESMÁSTARDE, ESO;

SI ANTES ERA ESO, ENTONCES AHORA ES ESTO.

Lo más llamativo de los experimentos de Fuster y su equipo es el carácter compartido de las redes de memoria, cognits para el reconocimiento de patrones ya sean visuales, auditivos o verbales. Muchas áreas corticales se activan y las mismas neuronas forman parte de distintas redes perceptuales en ese diálogo entre el córtex prefrontal y las áreas asociativas posteriores.

También la MPF, la nueva HTM y los cognits encajarían bien con el modelo neural para el lenguaje de Hagoort, que sugiere tres componentes en el procesamiento del lenguaje: memoria para 
almacenar y recuperar información, unificación para integrar distintos tipos de información y control que remitiría a la acción (Hagoort, 2005). También podemos decir que el lenguaje es un dispositivo computacional de carácter cognitivo que, siendo funcionalmente autónomo, no sería independiente en términos genéticos, neurobiológicos y evolutivos (Benítez-Burraco, 2009).

\subsection{Genética y lenguaje}

La dependencia genética del lenguaje se presenta complicada. La diversidad de patrones en el lenguaje humano puede derivarse de la interacción con la evolución cultural, a partir de la naturaleza de la cognición, el sistema perceptivo y motor, limitaciones en el aprendizaje y sus procesos. Los genes para el lenguaje podrían haber evolucionado sólo con aspectos muy estables o básicos de los mecanismos lingüísticos. Propiedades del lenguaje, que cambien con las convenciones culturales, no pueden estar en el genoma, que cambia mucho más lento que la cultura (Chater y otros, 2009).

¿Qué pasa, pues, con FOXP2, brillante encuentro de un gen asociado al lenguaje específicamente? No parece que esté ligado a propiedades arbitrarias del lenguaje. Influiría en sistemas de aprendizaje de dominio general procedural (Fisher, 2006).

Los genes no especifican comportamientos o procesos cognitivos directamente. Son factores reguladores, marcadores de moléculas, receptores, encimas, etc., que interactúan en redes complejas, modulados por influencia del entorno para mantener al cerebro. En toda esta producción científica sobre FOXP2 se ha encontrado que su homólogo (FoxP2) se relaciona en el caso de algunos pájaros con la adquisición social del canto y con los niveles de expresión del gen en la llamada área $X$, componente del circuito cerebral anterior vinculado al aprendizaje del canto y con correspondencia en los ganglios basales humanos, donde también se manifiesta FOXP2 (Lorenzo, 2009).
Pájaros y humanos pueden haber desarrollado independientemente habilidades de tipo combinatorio, modificando mínimamente la misma red de regulación génica de la que FOXP2 forma parte. Parece funcionar en un componente de memoria, en el córtex y otro componente, generador de patrones, en los ganglios basales. Deberíamos recordar a Darwin de nuevo.

Parece que la evolución del lenguaje humano se entenderá en términos de evolución cultural. Y en cuanto al lenguaje como adaptación biológica, sólo en aquellas estructuras profundas que presentan una disposición al aprendizaje jerárquico en la estructura preexistente del neocórtex.

La genética del lenguaje quedará integrada en la génesis de un funcionamiento común de organización jerárquica y capacidad de hacer prototipos, patrones, modelos, de modelizar la realidad, característica vital de la evolución a la cognición humana defendida por Hawkins y conectada vitalmente a las habilidades sociales de la humanidad a través del sistema de neuronas espejo y la memoria, como también defienden Ramachandran (2011), Rizolatti (2006) y Fuster (2006).

El lenguaje tiene una componente innata en el cerebro humano, en cuanto a que su estructura responde a la manera de aprender del cerebro y gestionar los modelos memorísticos en los procesos cognitivos. Pero no hay una maquinaria exclusiva para el lenguaje en la dotación genética, sino que seguramente está relacionada con el resto de sistemas cognitivos, perceptuales y motores con un mayor o menor reflejo del lenguaje en algún proceso de cognición, que serían los casos de daños en el lenguaje no sobrevenidos: tiene que haber otras alteraciones cognitivas o de aprendizaje junto con ellas. Que algo se manifieste en el lenguaje no tiene por qué ser para el lenguaje exclusivamente.

La existencia de unos algoritmos comunes, aunque con excepciones, en el proceso de 
aprendizaje hebbiano del neocórtex, facilita la comprensión de la marca genética para el lenguaje y otras habilidades corticales superiores que compartirían procesos semejantes de aprendizaje, tal como postula la teoría del marco memoria-predicción y la HTM. Sin embargo, esta teoría, que parece abrir un camino prometedor hacia máquinas inteligentes en los próximos años y explicar un concepto de inteligencia compatible con la evolución, no explica aún las especializaciones modulares del neocórtex durante la ontogénesis ni ha progresado aún más allá de modelos bayesianos de aprendizaje básico. La conexión con los cognits de Fuster parece mostrar un camino en el que la memoria, la capacidad de almacenar información del cerebro, y el aprendizaje de patrones dan una buena conexión para ver el diálogo entre genotipo y fenotipo a lo largo de las dos evoluciones, la cultural social y la natural genética.

\section{Conclusiones}

La memoria juega un papel dominante en el funcionamiento cognitivo. La imagen que se está formando del lenguaje en el córtex humano es la de redes activas, extensas y complejas con contenidos cognitivos que operan algoritmos comunes a muchas demandas y son esenciales, en concreto, para la comprensión y expresión del lenguaje. Podemos hablar de patrones de memoria que construyen modelos de predicción, modelos temporales jerárquicos de memoria, como defiende Hawkins, o, como propugna Fuster, cognits, redes neuronales que incluirían la atención, la memoria de trabajo, auditiva y visual con acceso a la memoria a largo plazo. Es verdad que el proceso constructivo del lenguaje se encuentra en parte en dos grandes áreas del hemisferio izquierdo, Wernicke para el significado y Broca en la expresión sintáctica, pero sus procesos no se pueden concebir sin la contribución cognitiva en múltiples redes compartidas con un algoritmo común en la fabricación incesante de patrones en todo el neocórtex (Hawkins y Blakeslee, 2004). No parece razonable construir módulos lingüísticos o áreas dedicadas al lenguaje fuera del contexto general de la cognición (Fuster, 2003). Tanto estas bases cognitivas como las operaciones del lenguaje muestran una plasticidad grande en la adaptación del humano a su entorno, a partir de un mecanismo genético común de construcción de modelos en continuo cambio. Si es así, el lenguaje ha evolucionado para ajustarse al cerebro humano y sus previamente desarrollados sistemas de cognición, mediante la memoria y aprendizaje, y no al revés.

\section{Bibliografía citada}

BACH-Y Rita, Paul, 2004: "Tactile sensory substitution studies", Ann N Y Acad Sci 1013, 83-91.

BAKER, Mark, 1996: The polysynthesis parameter, New York: Oxford University Press.

Benitez-Burraco, Antonio, 2009: "Biolingüística: A la espera de nuevos datos (biológicos)... para resolver viejas controversias (lingüísticas)", Ludus Vitalis, vol. XVII. n. 32.

Buxhoeveden, Daniel y Manuel Casanova, 2002: "The minicolumn hypothesis in neuroscience", Brain 125, 935-951.

Cavalli-Sforza, Luigi, 1996: Geni, popoli e lingue, Milán: Adelphi.

Changizl, Mark, Qiong Zhang, Hao Ye y Shinsuke SHImojo, 2006: "The Structures of Letters and Symbols throughout Human History Are Selected to Match Those Found in Objects in Natural Scenes", The American Naturalist 167, 5.

Chater, Nick, Florencia Reali y Morten Christiansen, 2009: "Restrictions on biological adaptation in language evolution”, Pnas 106, 4, 1015-1020.

Chomsky, Noam, 1959: "A Review of B.F. Skinner's Verbal Behavior", Language 35, 26-58.

DawkIns, Richard, 1989: The Selfish Gene, Oxford: Oxford University Press. 
Dileep, George y Jeff Hawkins, 2005: "A hierarchical Bayesian model of invariant pattern recognition in the visual cortex", Proceedings of the International Joint Conference on Neural Networks, 3, 1812-1817.

DileEp, George, 2008: How the brain might work: a Hierarchical and Temporal Model for Learning and Recognition. Tesis doctoral, Stanford: Stanford University.

Edelman, Gerald Maurice, 2006: Second Nature. Brain Science and Human Knowledge, New Haven London: Yale University Press.

Feldman, Jerome, 2005: "On intelligence as memory”, Artificial Intelligence 169, 181-183.

Fisher, Simon, Faraneh Vargha-Khadem, Kate WatkIns, Anthony Monaco y Marcus Pembrey, 1998: "Localisation of a gene implicated in a severe speech and language disorder", Nature Genetics 18.

Fisher, Simon, 2006: "Tangled webs: Tracing the connections between genes and cognition", Cognition 101, 2, 270-297.

Fuster, Joaquin, 2003: Cortex and Mind. Unifying Cognition, New York: Oxford University Press. Fuster, Joaquin, 2006: "Cortical Dynamics of Working Memory", Lecture 8 of 12 of IBM Research's Almaden Institute Conference on Cognitive Computing.

GopnIK, Myrna, 1990: "Feature-blind grammar and dysphasia”, Nature 344, 715.

Greenfield, Patricia, 1991: "Language, tools and brain: The ontogeny and phylogeny of hierarchically organized sequential behavior", Behav. Brain Sci. 14, 531-595.

HaGooRt, Peter, 2005: "On Broca, brain and binding: A new framework", Trends in Cognitive Sciences 6, 78-84.

Hawkins, Jeff y Sandra Blakeslee, 2004: On Intelli- gence, New York: Henry Holt and Company.

Hawkins, Jeff, Subutai Ahmad y Donna Dubinsky, 2011: Hierarchical Temporal Memory including HTM Cortical Learning Algorithms. Version 0.2.1, California: Numenta, Inc.

Lal, Cecilia, Simon Fisher, Jane Hurst, Faraneh VARGHA-Khadem y Anthony Monaco, 2001: "A forkhead domain gene is mutated in a severe speech and language disorder", Nature 413, 519-523.

LonGA, Víctor Manuel, 2003: "Genética y lenguaje”, Mètode 39, Valencia: Departamento de Teoría de los Lenguajes, Universitat de València.

Lorenzo, Guillermo, 2009: "Darwin y la facultad (no tan) humana del lenguaje”, Ludus Vitalis, vol. XVII, 32.

Melchner, Laurie von, Sarah Pallas y Mriganka Sur, 2000: "Visual behaviour mediated by retinal projections directed to the auditory pathway", $\mathrm{Na}$ ture 404 (6780), 871-876.

Milner, David y Melvyn Goodale, 2006: The Visual Brain in Action, Norfolk: Oxford University Press.

MountCASTLE, Vernon Benjamin, 1978: "An organizing principle for cerebral function: the unit module and the distributed system" en Gerald Maurice Edelman y Vernon Benjamin Mountcastle (eds.): The Mindful Brain, Cambridge, MA: MIT Press. MountCASTLE, Vernon Benjamin, 1997: "The columnar organization of the neocortex", Brain 120(4), 701-722.

MountCAstLe, Vernon Benjamin, 1998: Perceptual Neuroscience. The cerebral cortex, Cambridge, Massachusetts: Harvard University Press.

MountCastle, Vernon Benjamin, 2003: "Introduction (special issue)", Cerebral Cortex 13, 1.

NoË, Alva, 2009: Out of Our Heads. Why are you not your brain and other lessons from the biology of consciousness, New York: Hill and Wang.

PInker, Steven, 1991: "Rules of language", Science 
253, 530-535.

PINKER, Steven, 2006: "Mirror Neurons and the Brain in the Vat", The Third Culture, Edge Foundation, Inc. [http://bit.ly/TS67f, fecha de consulta: 11 de junio de 2012].

PInker, Steven, 2011: The Tell-Tale Brain, New York: W.W. Norton \& Company Inc.

RamaChAndRAN, Vilayanur, 2000: "Mirror Neurons and imitation learning as the driving force behind 'the great leap forward' in human evolution", The Third Culture, Edge Foundation, Inc. [http://bit.ly/2Lvo, fecha deconsulta: 11 de junio de 2012].

Ramachandran, Vilayanur, Lindsay Oberman, 2006: "Broken Mirrors", Scientific American 295(5), 6269.

RamaCHANDRAN, Vilayanur, Diane Rogers-RamaCHANDRAN y Steve COBB, 1995: "Touching the phantom", Nature 377, 489-490.

Ramos-Zúñiga, Rodrigo y Teresita de Jesús VilLASEÑOR-Cabrera, 2011: "Psico y neurobiología del lenguaje y la comunicación humana”, Máster Internacional en Psicobiología y Neurociencia Cognitiva, Barcelona: Viguera.

RICHARDS, Robert, 1987: Darwin and the emergence of evolutionary theory of mind and behavior, Chicago: University of Chicago Press.

Sacks, Oliver, 2010: The mind's eye, New York: Random House Inc. Borzoi Book.

Salas, Margarita, 2003: "Genética y Lenguaje”, texto del discurso de Ingreso en la Real Academia Española [http://bit.ly/qNIMqo, fecha de consulta: 11 de junio de 2012].

Serrano, Sebastián, 2003: "Proceso de hominización y lenguaje" Mètode 39, Valencia: Departamento de Teoría de los Lenguajes, Universitat de València.

WiLson, Edward, 1978: On human nature, Cambridge, MA: Harvard University Press. 